\title{
APPLICATION OF SCHOOL LITERACY MOVEMENT PROGRAM (GLS) IN ELEMENTARY SCHOOL MATHEMATICS LEARNING
}

\author{
Novy Trisnani \\ IKIP PGRI Wates \\ novy_trisnani@yahoo.com
}

\section{Article History}

accepted 30/09/2018

approved 12/10/2018

published 30/10/2018

\section{Keywords}

School Literacy Movement Program(GLS), learning, mathematics in elementary school

\begin{abstract}
The School Literacy Movement Programis a form of government concern for the low competency of Indonesian students in the fields of mathematics, science, and reading. The implementation of GLS in learning in elementary schools is carried out in four stages, preparation, implementation, monitoring, and evaluation stages. GLS at the preparation stage in mathematics learning, including the provision of integrated mathematics learning based on literacy, and at the implementation stage are structured literacy learning classes, and the organization of literacy-based mathematics materials. The application of GLS in learning mathematics in elementary school is very important to build students 'understanding, writing skills, and communication skills by increasing understanding of reading texts in all subjects and improving students' high thinking skills (Higher Order ThinkingSkill/HOTS).
\end{abstract}

Social, Humanities, and Education Studies (SHEs): Conference Series https://jurnal.uns.ac.id/shes 


\section{PENDAHULUAN}

Keterampilan membaca berperan penting dalam kehidupan kita karena pengetahuan diperoleh melalui membaca.Oleh karena itu, keterampilan ini harus dikuasai peserta didik dengan baik sejak dini.Dalam uji literasi yang dilakukan oleh PIRLS 2011, Indonesia menduduki peringkat ke-45 dari 48 negara peserta dengan skor 428 dari skor rata-rata 500 (IEA, 2012).Sementara itu, dalam uji literasi membaca oleh PISA pada 2012 menunjukkan peserta didik Indonesia berada pada peringkat ke64 dengan skor 396 (skor rata-rata OECD 496) (OECD, 2014).Data PIRLS dan PISA tersebut menunjukkan bahwa kompetensi peserta didik Indonesia tergolong rendah, khususnya dalam keterampilan memahami bacaan.Data ini selaras dengan temuan CCSU (2017) terkait negara paling literat di dunia (World's Most Literate Nation) yang menempatkan Indonesia pada peringkat 60 dari 61 negara yang disurvei.

Hasil tes kemampuan matematika oleh PISA (2015) dan TIMSS (2016), menunjukkan hal yang hampir sama, yaitu Indonesia menduduki peringkat bawah, bahkan di bawah Vietnam, sebuah negara kecil di Asia Tenggara yang baru saja merdeka. Hasil tes matematika yang diselenggarakan PISA, menunjukkan skor nilai antara Vietnam dan Indonesia terpaut sangat jauh.Vietnam mendapatkan nilai 495 (dengan nilai rata-rata 490), sedangkan Indonesia mendapatkan nilai 387.Begitupun hasil tes matematika oleh TIMMS, Indonesia mendapatkan nilai 395 dari nilai rata-rata 500.Nilai tertinggi didapatkan Singapura dengan nilai 618 (50\% lebih tinggi daripada Indonesia).

Gerakan Literasi Sekolah yang digagas dan dikembangkan Direktorat Jenderal Pendidikan Dasar dan Menengah merupakan kepedulian atas rendahnya kompetensi peserta didik Indonesia dalam bidang matematika, sains, dan membaca.Melalui penguatan kompetensi literasi, terutama literasi dasar, peserta didik diharapkan dapat memanfaatkan akses lebih luas pada pengetahuan agar rendahnya peringkat kompetensi tersebut dapat diperbaiki.

Kompetensi literasi dasar (menyimak-berbicara, membaca-menulis, berhitungmemperhitungkan, dan mengamati-menggambar) sudah selayaknya ditanamkan sejak pendidikan dasar, lalu dilanjutkan pada jenjang pendidikan yang lebih tinggi agar peserta didik dapat meningkatkan kemampuan untuk mengakses informasi dan pengetahuan.Gerakan Literasi Sekolah (GLS) adalah upaya menyeluruh yang melibatkan semua warga sekolah (guru, peserta didik, orang tua/wali murid) dan masyarakat, sebagai bagian dari ekosistem pendidikan.GLS mengarahkan seseorang pada kemampuan memahami pesan yang diwujudkan dalam berbagai bentuk teks (lisan, tulis, visual) (Dewi, 2016). Dalam tulisan ini akan dibahas tentang penerapan GLS dalam menunjang pembelajaran matematika di Sekolah Dasar.

\section{HASIL DAN PEMBAHASAN}

Gerakan Literasi Sekolah (GLS) merupakan gerakan adalah gerakan yang dilaksanakan di sekolah dalam rangka mengubah fungsi sekolah sebagai organisasi pembelajaran yang berupaya menjadikan semua warganya menjadi terampil membaca untuk mendukung mereka sebagai pembelajar sepanjang hayat (Strategi Literasi di SD, 2018).Dalam Gerakan Literasi Sekolah (GLS) pihak yang dilibatkan adalah semua pemangku kepentingan di bidang pendidikan, mulai dari tingkat pusat, provinsi, kabupaten/kota, hingga satuan pendidikan.Selain itu, pelibatan unsur eksternal dan unsur publik, yakni orang tua peserta didik, alumni, masyarakat, dunia usaha dan industri juga menjadi komponen penting dalam GLS.Lebih lanjut, Miaz (2017: 7) menegaskan bahwa tujuan umum dari GLS di SD adalah untuk menumbuhkembangkan budi pekerti peserta didik melalui pembudayaan suasana literasi sekolah yang diwujudkan dalam gerakan literasi sekolah. Sedangkan tujuan khusus GLS di SD yaitu: (1) menumbuhkembangkan budaya literasi di sekolah, (2) meningkatkan kapasitas literasi warga dan lingkungan sekolah, (3) menjadikan sekolah 
sebagai taman belajar yang menyenangkan agar warga sekolah mampu mengelola pengetahuan dan menjaga keberlanjutan pembelajaran dengan menghadirkan beragam buku bacaan, dan (4) mewadahi berbagai strategi membaca bagi warga dan lingkungan sekolah.

Untuk memastikan keberlangsungannya dalam jangka panjang, GLS SD dilaksanakan dalam tiga tahap, yaitu tahap pembiasaan, pengembangan, dan pembelajaran.

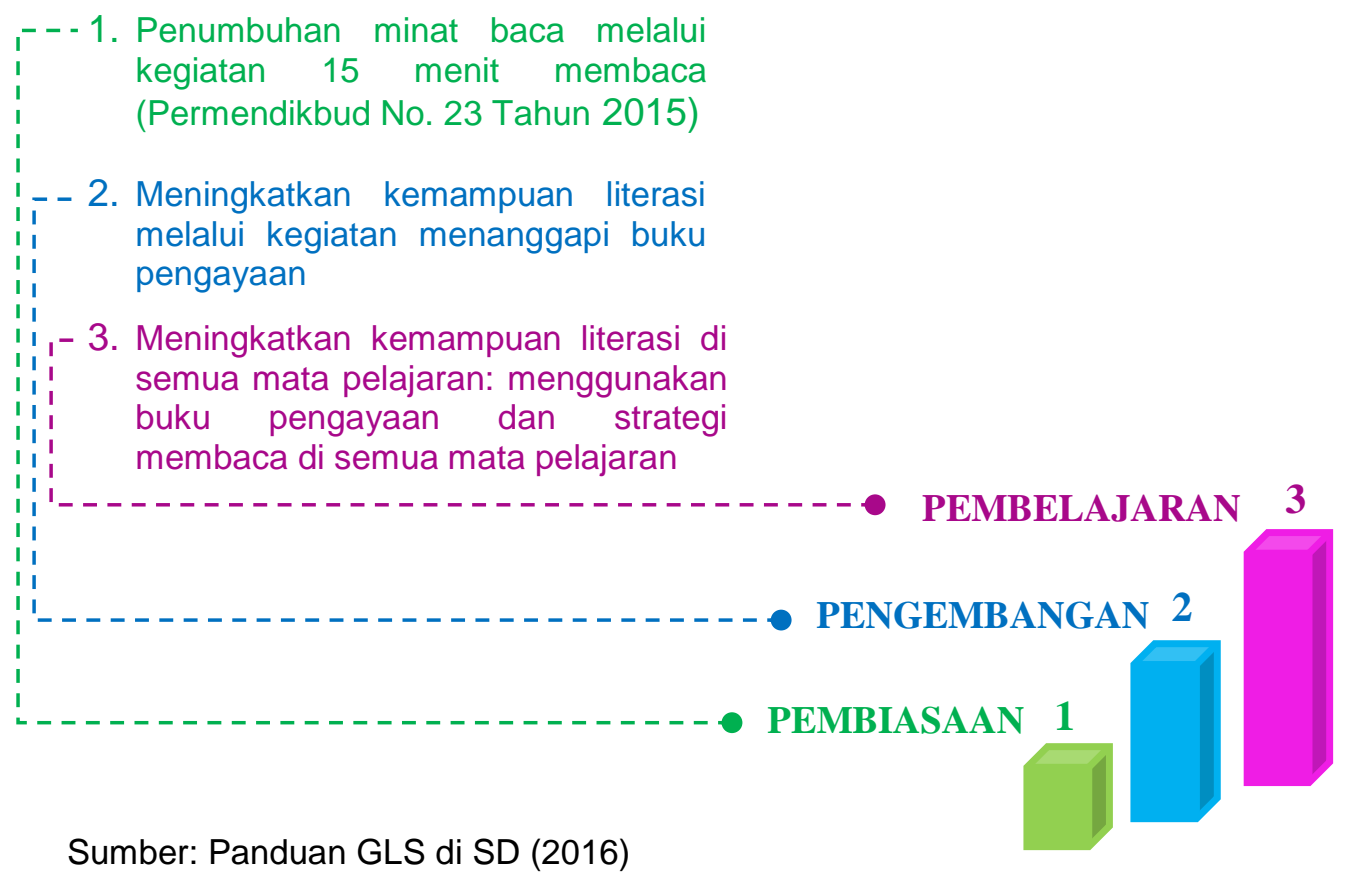

Dalam penelitian ini akan dibahas tentang penerapan GLS pada tahap pembelajaran, khususnya pembelajaran matematika. Kegiatan GLS pada tahap pembelajaran bertujuan untuk mempertahankan minat peserta didik terhadap bacaan dan terhadap kegiatan membaca, serta meningkatkan kecakapan literasi peserta didik. Langkahlangkah dalam penumbuhan budaya literasi disekolah dasar adalah sebagai berikut: persiapan, pelaksanaan, pemantauan, evaluasi, dan tindak lanjut. Adapun peta pengembangan GLS di SD (Panduan GLS di SD, 2016) pada tahap pembelajaran adalah:

1. Menyediakan pembelajaran terpadu berbasis literasi

2. Menata kelas berbasis literasi

3. Mengorganisasikan material

4. Melaksanakan literasi terpadu sesuai dengan tema dan mata pelajaran

5. Membuat jadwal

6. Asesmen dan Evaluasi

7. Konferensi literasi warga sekolah

Berdasarkan langkah-langkah dalam penumbuhan budaya literasi disekolah, dalam tulisan ini akan dibahas tentang langkah persiapan dan pelaksanaan terutama penerapannya dalam pembelajaran matematika SD.

\section{LITERASI DALAM PEMBELAJARAN MATEMATIKA}

Literasi arti dasarnya adalah "melek", yang biasanya digunakan pada suatu konteks "melek huruf", "melek aksara", "melek teknologi", dan akhirnya istilah itu berkembang dengan cepat dan digunakan pada banyak konteks termasuk dalam 
pembelajaran matematika dan pembelajaran umumnya pada semua mapel(Strategi Literasi di SMK, 2017). Literasi dalam pembelajaran matematika dapat dimaknai sebagai bentuk kompetensi yang dibangun agar peserta didik kita paham, mengerti, terampil dalam materi matematika. Untuk itu perlu adanya upaya-upaya nyata dalam proses pembelajaran agar sikap, perilaku, dan segala tindakan belajar peserta didik dapat berkembang ke arah "melek matematika". Untuk mencapainya perlu dipikirkan dan dikembangkan penyusunan rancangan dan pembelajaran dikelas agar peserta didik mampu mengembangkan dirinya pada banyak aspek.

Selama ini berkembang pendapat bahwa literasi hanya ada dalam pembelajaran bahasa atau di kelas bahasa.Pendapat ini tentu saja tidak tepat karena literasi berkembang rimbun dalam bidang matematika, sains, ilmu sosial, teknik, seni, olahraga, kesehatan, ekonomi, agama, prakarya, dll (Robb, 2003).Literasi dalam pembelajaran matematika lebih dari sekadar membaca dan menulis, namun mencakup kemampuan siswa dalam menganalisa, memberikan alasan, dan menyampaikan ide secara efektif, merumuskan, memecahkan, dan menginterpretasi masalah-masalah matematika dalam berbagai bentuk dan situasi. Termasuk didalamnya adalah keterampilan berpikir menggunakan sumber-sumber pengetahuan dalam bentuk literasi cetak, visual, digital, dan auditory. Konten dalam pembelajaran matematika adalah apa yang diajarkan, adapun literasi adalah bagaimana mengajarkan materi matematika tersebut.

\section{PENERAPAN GLS DI SEKOLAH DASAR}

Implementasi penumbuhan budaya literasi di sekolah memerlukan langkahlangkah sebagai berikut: persiapan, pelaksanaan, pemantauan, evaluasi, dan tindak lanjut. Persiapan merupakan kegiatan menyiapkan bahan, personal, dan strategi pelaksanaan.Pelaksanaan merupakan operasionalisasi yang telah dipersiapkan. Berikut akan dibahas penerapan GLS pada tahap persiapan dan pelaksanaanya dalam pembelajaran matematika SD. Dalam tahap persiapan GLS pada pembelajaran matematika, termasuk didalamnya adalah menyediakan pembelajaran matematika terpadu berbasis literasi, dan pada tahap pelaksanannya adalah penataan kelas pembelajaran matematika berbasis literasi, dan pengorganisasian materi matematika berbasis literasi.

1. Perencanaan

Pada tahap perencanaan, hal perlu dilakukan adalah menyediakan pembelajaran matematika terpadu berbasis literasi, dengan cara:

a. Penerapan strategi literasi

Dalam rangka menyediakan pembelajaran matematika terpadu berbasis literasi, guru perlu menerapkan strategi literasi dalam pembelajaran. Strategi literasi dalam pembelajaran adalah cara atau siasat guru mengoptimalkan kegiatan pembelajaran dengan melibatkan kemampuan siswa dalam menyimak, berbicara, membaca, dan menulis untuk memproduksi ide dan mengkonstruksi makna yang terjadi dalam konteks tertentu mulai dari perencanaan, pelaksanaan, dan penilaian untuk mencapai tujuan pembelajaran. Tujuan utama penggunaan strategi literasi dalam pembelajaran adalah untuk membangun pemahaman siswa, keterampilan menulis, dan keterampilan komunikasi secara menyeluruh bukan saja pada mata pelajaran bahasa Indonesia.

Strategi literasi dalam pembelajaran terdapat dalam kegiatan sebelum, selama, dan setelah membaca, serta alat bantu yang digunakan. Kegiatan sebelum membaca antara lain (a) mengidentifikasi tujuan membaca, (b) membuat prediksi. Kegiatan selama membaca (a) mengidentifikasi informasi yang relevan, (b) mengidentifikasi kosakata baru, kata kunci, dan/atau kata sulit dalam teks, (c) mengidentifikasi bagian teks yang 
sulit(jika ada) dan/atau membaca kembali bagian itu, (d) memvisualisasi dan atau think aloud, (e) membuat inferensi (f) membuat pertanyaan tentang isi teks dan hal-hal terkait dengan topik tersebut (dapat menggunakan sumber di luar teks atau buku pengayaan), (g) membuat keterkaitan antarteks. Kegiatan setelah membaca antara lain (a) membuat ringkasan, (b) mengevaluasi teks, (c) mengubah dari satu moda ke moda yang lain, (d) memilih, mengombinasikan, dan atau menghasilkan teks multimoda untuk mengomunikasikan konsep tertentu, (e) mengonfirmasi, merevisi, atau menolak prediksi. (Kisyani, dkk., 2017).

b. RPP berbasis Literasi

Tahap pertama dalam pembelajaran yaitu perencanaan pembelajaran yang diwujudkan dengan kegiatan penyusunan rencana pelaksanaan pembelajaran (RPP).Strategi literasi dapat diintegrasikan dalam model dan pendekatan pembelajaran.Salah satu pendekatan pembelajaran yang mampu memfasilitasi literasi matematika siswa sekolah dasar yaitu PMRI. Menurut Sennen (2018) pembelajaran literasi matematika yang berbasis PMR merupakan suatu bentuk pembelajaran yang perlu dibangun agar siswa memiliki pengetahuan dan keterampilan matematika, pembelajaran yang memungkinkan siswa dapat mengetahui, memahami, mengerti, dan memiliki keterampilan matematika yang baik, siswa menguasai materi matematika dan memiliki nilai-nilai yang dibangun pada mata pelajaran matematika. Menurut Milah, Fahmi, dan Aep (2018), langkah pembelajaran dalam PMRI secara langsung memfasilitasi literasi matematika siswa sekolah dasar yang esensinya adalah mampu mengetahui, memahami dan menggunakan konsep dasar matematika untuk digunakan dalam kehidupan sehari-hari termasuk dalam pendidikan yang lebih lanjut. Guru dapat mengimplemetasikan PMRI untuk mengembangkan literasi matematika siswa melalui proses pembelajaran.

Strategi literasi yang diintegrasikan siklus pembelajaran dari tahap pendahuluan, inti, dan penutup, dapat diamati kemunculan indikator literasi dalam pembelajaran mulai dari guru membuka pelajaran hingga menutup pelajaran.Semakin banyak indikator literasi yang muncul dalam pembelajaran, berarti semakin syarat strategi literasi.Dalam kurikulum 2013 revisi tahun 2017 RPP yang dibuat oleh para tenaga pengajar harus memunculkan dan memasukkan 4 hal, yaitu Penguatan Pendidikan Karakter (PPK) , literasi, 4C (Communication, Collaboration, Critical Thinking and Problem Solving, dan Creativity and Innovation), dan Higher Order of Thinking Skill (HOTS), untuk itu diperlukan kreatifitas guru agar

2. Pelaksanaan bisa merangkainnya menjadi RPP yang utuh.

Dalam pelaksanaan kegiatan GLS di Sekolah Dasar, hal pertama yang dapat kita lakukan adalah dengan menata kelas berbasis literasi dan mengorganisasikan materi pembelajaran matematika yang berbasis literasi.

1) Menata atau menyetel kelas berbasis literasi 2018),

Berikut ini adalah contoh kelas kaya literasi (Strategi Literasi di SD, 


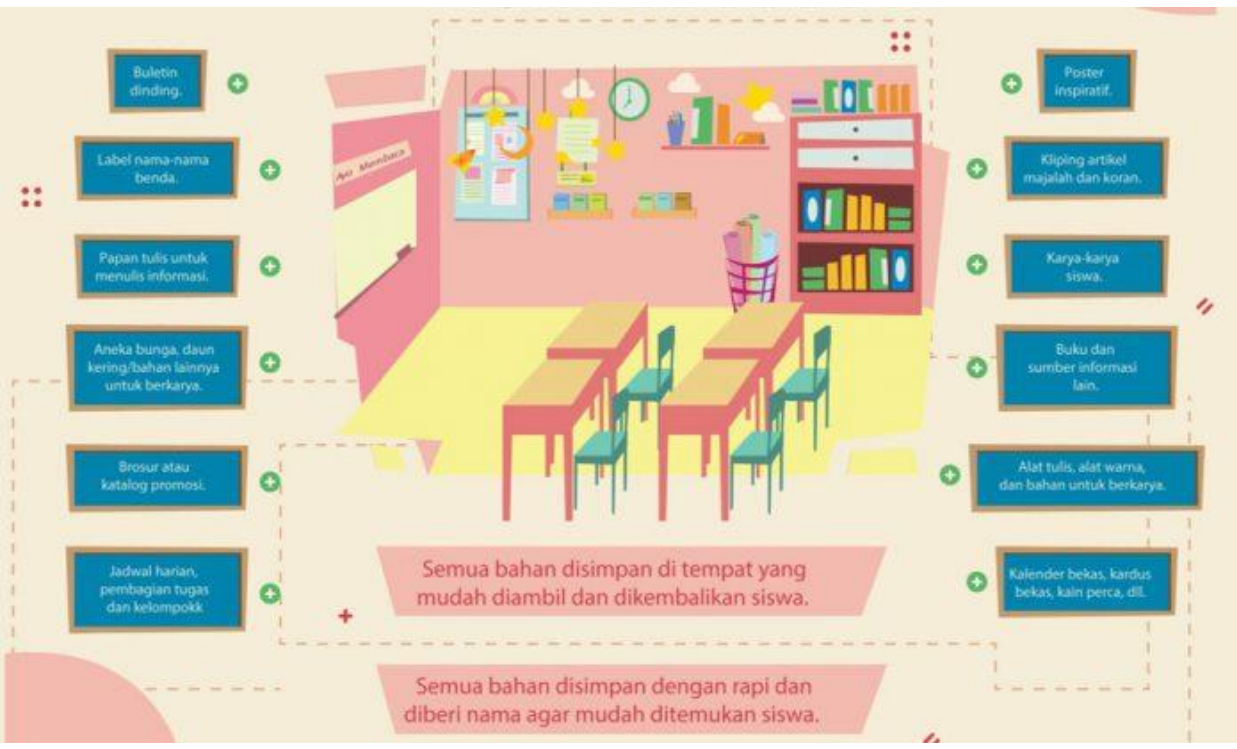

2) Mengorganisasikan materi matematika berbasis literasi.

Materi matematika berbasis literasi adalah materi matematika yang didalammnya memuat terdapat permasalahan dalam kehidupan sehari-hari yang menuntut siswa untuk merumuskan, mengunakan dan menafsirkan matematika secara efisien.Matematika yang dimaksudkan mencakup seluruh konsep, prosedur, fakta dan alat matematika baik dari sisi perhitungan, angka maupun keruangan. Dari segi proses, kemampuan ini tidak hanya terbatas pada kemampuan menghitung saja akan tetapi juga bagaimana mengkomunikasikan, menalar dan proses berfikir matematis lainnya.

Materi matematika berbasis literasi hendaknya dapat memacu siswa bukan hanya pada kemampuan penguasaan materi saja akan tetapi hingga kepada pengunaan penalaran, konsep, fakta dan alat matematika dalam pemecahan masalah sehari-hari. Selain itu, materi matematika berbasis literasi juga harus menuntut seseorang untuk mengkomunikasikan dan menjelaskan fenomena yang dihadapinya dengan konsep matematika.Pemberian materi matematika berbasis literasi dapat membantu siswa untuk memiliki kekuatan untuk mengunakan pemikiran matematika dalam pemecahan masalah sehari-hari agar lebih siap menghadapi tantangan kehidupan.Pemikiran matematika yang dimaksudkan meliputi pola pikir pemecahan masalah, menalar secara logis, mengkomunikasikan dan menjelaskan. Pola pikir ini dikembangkan berdasarkan konsep, prosedur, serta fakta matematika yang relevan dengan masalah yang dihadapi (Stecey \& Tuner, 2015)

\section{SIMPULAN}

Literasi berkembang dalam berbagai bidang, antara lain matematika, sains, ilmu sosial, teknik, seni, olahraga, kesehatan, ekonomi, agama, prakarya, sehingga strategi literasi dalam pembelajaran dapat diterapkan di semua mata pelajaran, dan dapat dikembangkan oleh guru secara kreatif sehingga mampu mengembangkan kompetensi peserta didik. Penerapan GLS dalam pembelajaran matematika di SD diperlukan untuk membangun pemahaman siswa, keterampilan menulis, dan keterampilan komunikasi dengan cara meningkatkan pemahaman terhadap teks bacaan dalam semua mata pelajaran dan meningkatkan kemampuan berpikir tinggi siswa (Higher Order ThinkingSkill/HOTS).

Saat ini gerakan-gerakan literasi tengah digalakkan di seluruh lapisan masyarakat dalam dunia pendidikan pada khususnya.Pengembangan literasi dapat terjadi di semua mata pelajaran melalui upaya untuk meningkatkan kemampuan 
berpikir analitis, kritis, kreatif, dan memecahkan masalah.Untuk menunjang upaya tersebut, guru perlu memasukkan strategi literasi dalam pembelajarannya, sehingga guru dapat mengemas pembelajaran dengan lebih komplek serta dapat mengerahkan seluruh kemampuan siswanya baik itu sikap, pengetahuan maupun keterampilannya dengan dasar memberikan pengetahuan literasi yang baik kepada siswanya.Untuk mencapainya tentu saja guru perlu berupaya secara sistematis dan berkesinambungan meningkatkan kemampuan literasi siswa.

\section{DAFTAR PUSTAKA}

Dewi Utama Faizah, dkk. (2016). Panduan Gerakan Literasi Sekolah di Sekolah Dasar. Jakarta: Direktorat Pembinaan Sekolah Dasar Ditjen Dikdasmen.

Kisyani Laksono, dkk. (2017).Pengembangan Budaya Literasi dan Strategi Literasi dalam Pembelajaran di Sekolah Menegah Pertama. Jakarta: Satgas GLS Kemdikbud.

Miaz, Yalvenna. (2017). Inovasi Pembelajaran IPS SD berbasis IT dalam Mendukung Gerakan Literasi.Makalah yang disajikandalam seminar nasional HDPGSDI diBukittinggi pada 5 September 2017.

Milah Nurkamilah, M. Fahmi Nugraha, dan Aep Sunendar. (2018). Mengembangkan Literasi Matematika Siswa Sekolah Dasar Melalui Pembelajaran Matematika Realistik Indonesia.Jurnal THEOREMS (The Original Research of Mathematics) Vol. 2 No. 2, Januari 2018 hal. 70-79.

OECD. (2014). PISA 2012 Results: What Students Know and Can Do - Student Performance in Mathematics, Reading and Science (Volume I, Revised edition, February 2014). Paris: OECD Publishing, 2014.

Robb, L. (2003). Teaching Reading in Social Studies, Science, and Math: Practical Ways to Weave Comprehension Strategies Into Your Content Area Teaching. NewYork: Scholastic Professional Books.

Satgas GLS Ditjen Dikdasmen.(2018). Strategi Literasi dalam Pembelajaran di Sekolah Dasar (Modul Materi Penyegaran Instruktur Kurikulum 2013). Jakarta.

Sennen, Eliterius. (2018). Mengelola Pembelajaran Literasi Matematika Berbasis Pembelajaran Matematika Realistik Bagi Siswa Sekolah Dasar.Jurnal Pendidikan dan Kebudayaan Missio, Volume 10, Nomor 1, hal.79-83.

Stecey, K \& Tuner, R. (2015).Assessing Mathematical Literacy: The PISA experience.Australia: Springer. 